\title{
Article \\ A Predictive Maintenance System for Reverse Supply Chain Operations
}

\author{
Sotiris P. Gayialis (D), Evripidis P. Kechagias*(D), Grigorios D. Konstantakopoulos (D) and Georgios A. Papadopoulos
}

Sector of Industrial Management and Operational Research, School of Mechanical Engineering, National Technical University of Athens, 15780 Athens, Greece; sotga@central.ntua.gr (S.P.G.); gkonpoulos@mail.ntua.gr (G.D.K.); gpapado@mail.ntua.gr (G.A.P.)

* Correspondence: eurikechagias@mail.ntua.gr; Tel.: +30-210-7723526

Citation: Gayialis, S.P.; Kechagias, E.P.; Konstantakopoulos, G.D.; Papadopoulos, G.A. A Predictive Maintenance System for Reverse Supply Chain Operations. Logistics 2022, 6, 4. https://doi.org/ 10.3390/logistics6010004

Academic Editors: Rodrigo Goyannes Gusmão Caiado, Osvaldo Luiz Goncalves Quelhas and Luiz Felipe Scavarda

Received: 22 November 2021

Accepted: 5 January 2022

Published: 7 January 2022

Publisher's Note: MDPI stays neutral with regard to jurisdictional claims in published maps and institutional affiliations.

Copyright: (C) 2022 by the authors. Licensee MDPI, Basel, Switzerland. This article is an open access article distributed under the terms and conditions of the Creative Commons Attribution (CC BY) license (https:// creativecommons.org/licenses/by/ $4.0 /)$.

\begin{abstract}
Background: Reverse supply chains of machinery and equipment face significant challenges, and overcoming them is critical for effective customer service and sustainable operation. Maintenance and repair services, strongly associated with the reverse movement of equipment, are among the most demanding reverse supply chain operations. Equipment is scattered in various locations, and multiple suppliers are involved in its maintenance, making it challenging to manage the related reverse supply chain operations. Effective maintenance is essential for businesses-owners of the equipment, as reducing costs while improving service quality helps them gain a competitive advantage. Methods: To enhance reverse supply chain operations related to equipment maintenance, this paper presents the operational framework, the methodological approach, and the architecture for developing a system that covers the needs for predictive maintenance in the service supply chain. It is based on Industry 4.0 technologies, such as the Internet of things, machine learning, and cloud computing. Results: As a result of the successful implementation of the system, effective equipment maintenance and service supply chain management is achieved supporting the reverse supply chain. Conclusions: This will eventually lead to fewer good-conditioned spare part replacements, just in time replacements, extended equipment life cycles, and fewer unnecessary disposals.
\end{abstract}

Keywords: predictive maintenance; reverse supply chain; framework; methodology; industry 4.0; supply chain 4.0; Internet of things; machine learning; information system

\section{Introduction}

A reverse supply chain can be defined as the process of returning products or materials to the manufacturers for reusing, repairing, remanufacturing, recycling, or disposing of [1]. The services of equipment maintenance, repair, replacement are core reverse supply chain management operations related to the procedures of on-time returning equipment that need to be repaired or replaced. These services are strongly associated with the reverse movement of equipment and are considered reverse supply chain operations. These operations are not available in the forward supply chain where the flow of materials and products is determined by customer demand for supply. Instead, in the reverse supply chain, the flow follows the opposite direction and is determined by the need for repairs or returns. In order to achieve effective and efficient equipment maintenance, timely and systematic actions are necessary. More specifically, how promptly it is identified that equipment needs to be repaired or replaced and how rapidly the related reverse supply chain operations are executed, are determining factors for the smooth operation of industrial companies [2].

Equipment maintenance and repair services are, therefore, highly critical procedures of both the service supply chain, where they belong by definition as well as the broader reverse supply chain. If performed satisfactorily, they can become a means of gaining a competitive advantage and enhanced added value of services as perceived by customers. It should be noted that the service supply chain is part of the reverse supply chain related 
to after-sales support for products or services that need to be repaired or replaced. It primarily concerns the supply of spare parts, materials, technical personnel, and services required for the timely and efficient service of the operation of machines, for their repair and maintenance [3]. Often companies that sell or rent machines may also be responsible for their maintenance, involving various partners in the service supply chain such as repair shops and spare parts suppliers [4]. Maintenance is a hot issue for businesses as with the application of appropriate maintenance techniques, every business can have maximum benefits [5]. Predictive maintenance is an emerging approach to equipment maintenance, allowing users to reap the benefits of reducing maintenance costs while minimizing downtime [6]. It is applied using various technologies such as the Internet of things (IoT), cloud computing, advanced data analytics and augmented reality, from which each company can choose based on its needs. These technologies can be combined with information systems to improve equipment maintenance business processes $[7,8]$.

Nowadays, many companies undertake the monitoring and maintenance of the equipment they provide to their customers, such as professional refrigerators, professional washing machines, catering equipment, ICT equipment, medical equipment, industrial or other professional equipment. For these companies, the cost of maintenance of the equipment they have sold or rented to their customers (either through contracts for equipment operation or through leasing) is a significant percentage of their expenses [9]. This is usually due to the complexity and the high capital value of these assets as well as their ever-changing special operating conditions. In addition, this equipment often operates in remote and scattered locations, and its maintenance entails complex coordination and high costs [10].

The maintenance and repair issues as part of the reverse supply chains of the equipment create a significant challenge for most companies. Even though there have been many relevant research projects and studies, overcoming the challenges of reverse supply chain operations has yet to become adequately successful $[11,12]$. The main reason is that the central mechanism on which it is based cannot effectively manage critical factors such as the interests of supply chain members, the asymmetry of information in the maintenance processes, and the cost of quality tests and technical constraints [13-15].

Many efforts have been made for creating predictive maintenance systems, but most of them have failed to produce satisfactory results. These failures resulted due to the lack of technology that could support real-time monitoring, data collection, and decision making, but also due to a failure to make real changes in the workplace so that these technologies could be used to the fullest extent possible [14,16-18]. In order to obtain the maximum result from these solutions, radical changes need to be made to the way maintenance is applied in todays' companies [19-22].

Therefore, it becomes clear that effective reverse supply chain processes are a hot issue for involved companies [23-25]. Remote data collection and use for predictive maintenance is an emerging approach to improve reverse supply chain management of the machinery or equipment. Companies may benefit significantly by reducing the cost of maintenance work and returning defective products [26,27]. Fault diagnosis and prognosis in mechanical systems via data mining and data analysis is a research trend in the era of Industry $4.0[28,29]$.

Over the last few years, the Internet of things (IoT) and other Industry 4.0 technologies have started to be applied in the supply chain operations forming the supply chain 4.0 concept. This next-generation model for the supply chain involves the application of the aforementioned advanced technologies in order to achieve faster, more reliable, and more efficient operations [30,31]. From the maintenance point of view, the main idea is to use IoT sensors placed in every machine enabling communication between devices, systems, and the flow of information between them [32,33]. A network of smart sensors is created that operates by receiving real-time data of the condition of the equipment [34]. The collected data are analyzed using big data techniques in order to recognize patterns, 
identify the need for maintenance, and finally to improve the performance and reliability of the equipment $[35,36]$.

Preventive maintenance should not be treated as a substitute for traditional maintenance management methods. It is, however, a valuable addition to a complete on-site maintenance program. Where all maintenance programs are based on a scheduled repair of a machine or the rapid repair of a malfunction or breakdown, the predictive maintenance systems plan specific maintenance tasks proactively, whenever they are needed but not necessarily on a fixed maintenance schedule $[7,37,38]$. Although the need for the application of traditional maintenance methods cannot be eliminated, the use of advanced predictive maintenance systems can bring significant results to the operation of machines and plants. The predictive maintenance approach can effectively reduce the number of unexpected failures and thus offer a more reliable maintenance approach [39].

The benefits of implementing predictive maintenance systems depend on how they are implemented. If such a system is limited to predicting catastrophic failures, then it will only offer limited added value when utilized by companies. Similarly, if there is an exclusive focus on failure prevention (preventive maintenance), then this may result in an additional cost to the maintenance and operation of the machines [40,41]. It is, therefore, necessary to implement a predictive maintenance system following a holistic approach that will guarantee that it will be able to successfully cover the needs of the companies that decide to use it.

A predictive maintenance approach needs to be supported by an information system that is adapted to the needs of the specific equipment or business [42]. The case of equipment that is operating remotely in a wide variety of places has a lot of difficulties in planning and execution of its maintenance, due to the absence of effective monitoring of the equipment's condition and the need for mobile workshops to execute the maintenance or the repair of the machines $[43,44]$. Such a case is the leasing and operation of refrigerators in many different shops and in different operating conditions, where this equipment should be maintained regularly, repaired, or replaced when it becomes out of order. Similar cases that the equipment is installed at the customer's premises are the ICT equipment, the medical equipment, the professional washing machines, or other professional machines.

Predictive maintenance literature may be categorized into two major categories. The first one concentrates on creating prognostic models without performing decisionmaking [45-47]. The second one, on the other hand, performs maintenance optimization decisions using preexisting prognostic models [48-50]. However, none of the two categories manage to provide a holistic approach for creating prognostic models and then performing decision making so that it can be utilized for creating an effective predictive maintenance system. Therefore, this research gap of a holistic systemic approach has led to the formation of the present research. More specifically, the need for an information system that can create predictive models and perform decision-making on equipment maintenance in the service supply chain is discussed in this paper, and the design of such a system is presented.

In the remainder of the paper, after explaining the research methodology followed in this paper, the main contributions of the paper are presented thoroughly, i.e., the methodological approach, the operational framework, and the architecture for developing a predictive maintenance system supporting reverse supply chain operations. Section 2 presents the research methodology including the problem, the objective, and the research question as set by the authors. Section 3 discusses the methodological approach for developing the system by introducing the two main phases and explaining how the system can be successfully implemented. Section 4 analyses the system's operational framework and its main objectives which are supported by the system's main functionality. This section also presents the system's architectural design. Section 5, finally, discusses the results and benefits from the successful implementation of the system. 


\section{The Research Methodology}

The methodology followed in this paper is conceptual qualitative research in the field of system engineering [51,52]. Valuable information gathered from the scientific literature $[22,41,53,54]$ sets the theoretical background of the research. The followed methodology presents how the authors conceptualize the research problem, what do they identify as an objective, based on their knowledge and experience, and what research question should be answered as an outcome of their research. Therefore, the outcome of the research is a conceptual model that establishes a well-supported rationale and is organized in a manner that helps the reader understand and assess the authors' perspective.

More specifically, in this research, the investigated problem is the ineffective maintenance of equipment in the service supply chain. The objective of the research is to solve this problem through effective predictive maintenance that supports reverse supply chain operations. The research question, as set by the authors, is "How can professional equipment maintenance, supporting reverse supply chain operations, be performed effectively utilizing today's advanced technologies?"

After recognizing the gap in the literature, as explained in the Introduction section, the research team followed the aforementioned research methodology in order to answer the research question and overcome the identified research problem. The research team has a strong knowledge of predictive methods for equipment maintenance as part of the reverse supply chain. This is why they managed to present a holistic approach, in terms of a conceptual design for effective predictive maintenance supporting reverse supply chain operations as analyzed in Sections 3 and 4. This conceptual design is the main contribution/deliverable of the research and includes:

- The methodological approach for the development of a predictive maintenance system following a customized waterfall methodology;

- The system's operational framework including the methods and tools that are utilized;

- The architectural design of the system.

\section{The Methodological Approach for Developing the Predictive Maintenance System}

The advanced information system, as presented in this research, incorporates innovative predictive maintenance methods and techniques to optimize reverse supply chain operations while also effectively coordinating all parties involved. The research implementation methodology includes two phases (Figure 1) and is conducted by three partners, a research institution, a software development company, and an SME industrial company.

The first phase concerns the preparation of the research and the design of the system. It includes the study of technological excellence for the related research fields, the analysis of the operation of the studied remote equipment (professional washing machines), the identification of the critical parts of the equipment to monitor. This phase also includes selecting sensors for the implementation of the IoT monitoring of the operation for the remote equipment, and finally, the configuration of methods and algorithms that are implemented both for the collection and processing of data and for the prognosis of the maintenance need, as well as for the optimization of the service supply chain. The requirements of the system and the design specifications are the outcomes of the first phase of the methodological approach.

The second phase utilizes the results of the first phase in order to develop and install the designed predictive maintenance system. It includes the utilization of the technology for information system development and the implementation of the selected algorithms (e.g., data analysis algorithms or scheduling algorithms) as well as the methods for spare parts and maintenance services requirement planning. In this phase, the initial development of the advanced predictive system is achieved (prototype). It includes the installation of the sensors as well as the testing of the system in actual operating conditions in order to improve its functionality and make it appliable in real-life cases. Finally, this phase includes the final development of the predictive maintenance system, based on the improvements 
that are to be decided after the testing. This final version of the system has the potential to become a fully functional tool for effective predictive equipment maintenance.

\section{Phase 1 \\ Preparation \& Design}

Phase 2

System Development \& Installation
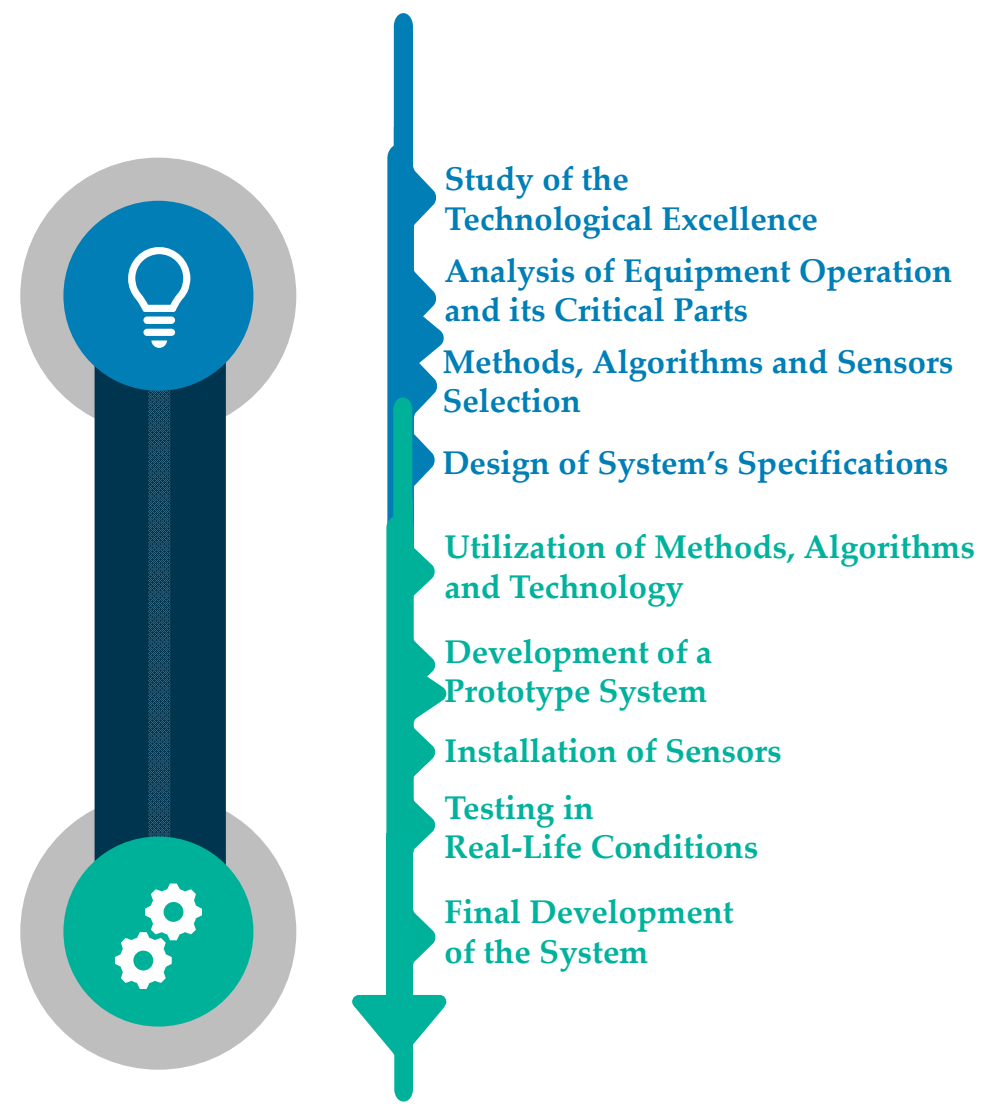

Figure 1. The Methodological Approach for Developing the Predictive Maintenance System.

In more detail, in the first phase, a thorough study is conducted concerning technological excellence in the fields of predictive maintenance and service supply chain. Additionally, this phase includes the analysis of machine learning and artificial intelligence algorithms for detecting impending failures in the supply chain optimization methods, the equipment, and the smart sensors. Finally, the advanced technologies needed for the system's successful implementation are also planned to be studied in this phase. In other words, this first phase covers both the technological excellence of methods and the technological solutions.

At the same time, the procedures of the reverse supply chain, the operation of the industrial equipment, and the maintenance processes are analyzed, while the critical points of the equipment are identified for the detection of impending failures as well as to find the data necessary to collect. At that point, the procedures are recorded in business process models, and use case scenarios are formulated, ultimately leading to the analysis of the new system's requirements and its technical and operational specifications. The sensors and smart devices that are evaluated as suitable for data collection and that can be utilized for the system's implementation are then identified. In addition, advanced machine learning algorithms are developed and can be fed with dynamically changing data in order to improve the predictive maintenance of the machines depending on the history of failures and their operational data. Finally, the appropriate methods for scheduling material supply and scheduling of maintenance workshop visits are formulated for the better management of the service supply chain and the efficient implementation of maintenance.

In the second phase, the system is implemented, taking into account the research analysis and the specifications resulting from the first phase. All selected methods, approaches, and technologies of Industry 4.0 are implemented in a unified software solution, utilizing advanced information technologies. This software can collect data from remote equipment, 
process it through advanced algorithms, and provide effective predictive maintenance. The system can successfully cover the needs of the companies that decide to use it by optimally managing the supply of materials and scheduling maintenance workshop visits and by coordinating the reverse supply chain processes and operations. The eventually developed system operates in the cloud, facilitating the interaction with smart sensors and the storage and management of large volumes of data.

The initially developed system, based on the methods and techniques that are formed in the first phase, is tested in various real-life cases. The system is tested with the aid of companies that both provide professional equipment (washing machines, refrigerators), and at the same time, are also responsible for its maintenance. Thus, the system is tested in actual operating conditions and real use case scenarios. Through the formulation of use case scenarios and real-life testing, the effectiveness of the methods and algorithms selected for the system is evaluated. Additionally, the technical implementation of the system and its integration with sensors and other systems is processed. The testing aims to lead to improvements implemented in the final version of the system to cover the demanding industrial needs effectively. At the same time, reference models of collaborative business processes are developed, supporting the system's installation in any company that decides to adopt the system in the future. In this way, it is ensured that the system can effectively support the predictive maintenance and reverse supply chain operations through collaborative procedures for all involved stakeholders: owner of the equipment, customersusers of the equipment, vendors of spare parts and materials, third-party warehouses, mobile maintenance workshops.

\section{Design of the Predictive Maintenance System}

This section focuses on presenting the operational framework of the advanced information system that incorporates innovative predictive maintenance methods and techniques to optimize the reverse supply chain operations and all the related maintenance, repair, and replacement procedures. This operational framework includes the system's functionality and the embedded methods and tools (a set of Industry 4.0 technologies and advanced algorithms for predictive maintenance purposes). It is supported by the aforementioned implementation methodology, as well as a conceptual schema for its architectural design.

\subsection{The System's Operational Framework, Objectives and Functionality}

The implementation of the system is based on emerging technologies of the Fourth Industrial Revolution (Industry 4.0), such as the Internet of things (IoT) for the collection of equipment operating data, machine learning algorithms, and artificial intelligence for predictive maintenance, as well as cloud computing technologies for the data processing and the system's offered functionality. In addition, the development of the predictive maintenance system follows modern approaches for the implementation of collaborative business processes of the reverse supply chain in order to coordinate the supplies of materials and spare parts as well as for the resource planning (maintenance workshops). Figure 2 diagrammatically depicts the operational framework of the system in terms of the system's functionality and the methods and techniques that are incorporated. The system's main functionality is depicted in Figure 2 as the top-down flow, while the embedded technologies and methods are mentioned on the left or the right side of the main functions.

The system has three main objectives which are supported by the system's main functionality. These objectives include:

1. The holistic adoption of predictive maintenance that supports companies to avoid damage, as well as unnecessary maintenance of the equipment and effective reverse supply chain operations, based on the methods and technologies of the Fourth Industrial Revolution.

2. The redesign of more effective and efficient reverse supply chain operations to achieve the formulation of optimal maintenance plans, including the schedule of maintenance workshop visits and the plans of spare parts and maintenance materials replenishments. 
3. The improvement and the expansion of the cooperation between companies involved in the supply chain (owners of assets, customers, suppliers, and third party service partners) through the adoption of modern approaches to implement collaborative business processes, including equipment providers (orchestrators), equipment users, maintenance and maintenance crews, suppliers of spare parts and materials, distributors and software providers.



Figure 2. The System's Operational Framework: Main Functionality and the Embedded Technologies and Methods.

Achieving the first objective, which is particularly critical to the research, requires effective prediction of impending failure, enabling immediate planning and targeted maintenance to avoid the breakdown. This is precisely the idea of predictive maintenance that the system can effectively perform. Maintenance is a process costly and challenging to implement to support the life cycle of a machine or technical part of any system. Applying effective preventive maintenance, the equipment is serviced at regular intervals according to schedule, whether it is really required or not, while during corrective maintenance, the equipment is repaired as soon as it fails. Both cases, however, result in increased costs as, in the first case, spare parts are serviced and replaced precautionarily without always being sure that it is required or at least that it is the right time, while, in the second case, extended downtime of the equipment is created which leads to inactivity for the whole system in which they belong.

Predictive maintenance can significantly contribute to early and on-time predictions for equipment repairing or replacement by combining the benefits of preventive and repressive maintenance. Its application, however, requires the continuous collection and processing of operating data of the equipment but also effective algorithms for the prediction of failure based on the data processing methods. Advances in technology can enable companies to monitor real-time equipment conditions from sensors and smart devices through the Internet of things (IoT) technology even if they are scattered in many different places and operate separately. 
At the same time, in addition to collecting equipment operating data in real-time, critical equipment failure prediction algorithms can be utilized. The predictions can be achieved by analyzing the data collected by smart sensors and combining it with historical operating and fault data to assess the condition of the equipment based on patterns that may be formed. These patterns of impending fault detection should be constantly reviewed as data are collected, following a learning process. For this reason, it is necessary to develop and utilize in the system machine learning algorithms or artificial intelligence techniques in order to be able to implement predictive maintenance effectively. The analysis of these data due to their volume requires the use of high computing power, and for this reason, cloud computing technology needs to be utilized.

Achieving the second objective requires the selection and adoption of supply chain planning and management methods. Specifically, methods for material and spare parts requirements planning, as well as scheduling of services provided by maintenance workshops, are to be selected and integrated into the system. These workshops can be privately owned or cooperative, but the planning and coordination of the execution of maintenance and service work are performed based on the needs of predictive maintenance. The need for maintenance workshops leads both to the management of the source of these services and to the planning of the visits to the premises where the equipment is located, preventing the impending faults. To schedule workshop visits, advanced algorithms are developed for routing the workshop visits at the equipment installation site.

The visits of the maintenance workshops are planned, having first ensured that the required spare parts and maintenance materials are available. For this purpose, methods of materials and spare parts planning are utilized, taking into account the maintenance needs that arise from the analysis of equipment operating data and the execution of predictive maintenance algorithms. The available stock, lead times, order lot sizes, and in general, the information related to the supply of materials and spare parts are also taken into account. These methods can be integrated into the system or also utilize the functionality of other systems such as enterprise resource planning (ERP) and warehouse management systems (WMS) of the enterprise through appropriate interfaces. From the completion of the predictive maintenance with the methods of planning and management of the reverse supply chain operations, the efficient maintenance of the equipment is achieved precisely at the required time (just in time) without unnecessary maintenance costs and the high costs involved by equipment inactivity.

Achieving the third objective requires the adoption of collaborative business processes, i.e., integrated business processes, based on reference models, which consist of relevant business processes across the involved partners. These processes are taken into consideration for the effective development of the predictive maintenance system as they set the path for the requirements and specifications analysis. Standard collaborative business processes for stakeholder coordination are designed in an appropriate business process modeling tool and using popular methods such as BPMN2 (Business Process Management Notation 2) or EPC (event-driven process chain) diagrams. The design of these processes complements and enhances the implementation of the system, ensuring effective predictive maintenance and optimization processes of the reverse supply chain.

\subsection{The System's Architectural Design}

The aforementioned functionality of the system is achieved through the architectural design depicted in Figure 3. In the next paragraphs, the system's main functionality of Figure 2 is related to the system's architecture of Figure 3. 


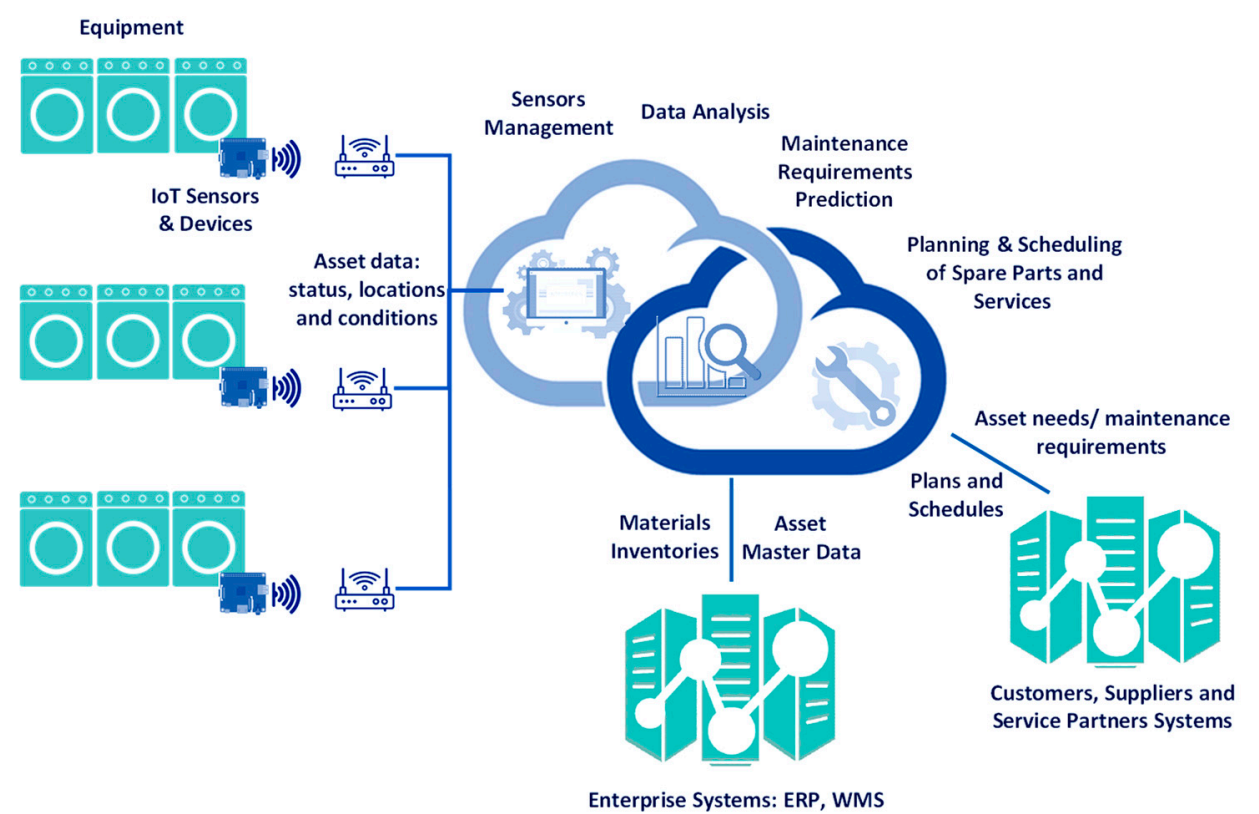

Figure 3. System's Architectural Design.

Monitor the operation of critical equipment: It is achieved using low-power IoT sensors and devices which monitor various measures, such as temperature, vibrations, and noise. The transfer of data is realized through wireless infrastructure and through the Internet. The equipment's data concerning its operation, its status, and conditions as well as its location are collected by a sensors management subsystem.

Analyzing operating data and prediction of maintenance requirement: All data collected are then analyzed using the cloud computing power of the system and appropriate algorithms (artificial intelligence and machine learning) in order to achieve the prediction of the maintenance requirements of the assets. This is the main outcome of the predictive maintenance procedure based on real data analysis of the equipment and prediction algorithms.

Materials and spare parts requirements planning and scheduling of services requirements: The maintenance requirements are transformed to purchase orders of materials and spare parts as well as to schedules of the mobile workshops concerning the date and time that they have to visit the locations of the maintained equipment. The materials requirements planning (MRP) algorithm is used to decompose the equipment bill of material $(\mathrm{BOM})$ to proceed with purchase orders if the inventories are not sufficient. For this functionality, integration with enterprise systems is necessary in order to use the asset's master data (BOM, materials master data, warranties, etc.) or current inventories levels and locations. Scheduling algorithms are also used for the time schedule of the tasks of the mobile maintenance workshops, including the sequence of visits

Inventory management, purchasing management and scheduling of maintenance teams: These functions are strongly related to the aforementioned functions in the context of the collaborative business processes. The maintenance requirements, the purchasing plans (of materials and services), and the schedules of maintenance workshops are transferred to customers (users of the equipment) and to vendors of the materials, spare parts, and maintenance services, using integration protocols with their systems. This functionality promotes the collaborative business processes concept, achieving successful replenishments of materials or spare parts, and suitable maintenance services, as these tasks are connected and interrelated.

Implementation and evaluation of the maintenance: following the maintenance schedules, predictive maintenance is achieved, and the results are recorded in order to evaluate the fulfillment of the schedules and the effectiveness of the predictive maintenance. 


\section{Discussion and Results}

The research efforts under discussion combine, in a comprehensive way, the implementation of the predictive maintenance approach, the support, and improvement of the reverse supply operations, the focus on innovative activities through the algorithms and technological approaches that the system incorporates from the field of the Fourth Industrial Revolution. All the above strengthen the effort for creating an effective predictive maintenance system with the ability to be implemented in a number of potentially interested companies that operate, monitor, and maintain equipment at the premises of their customers.

The predictive maintenance system can effectively support reverse logistics operations and the service supply chain. The system can support the operation and maintenance of equipment at scattered locations, coordinating all logistics processes involved in the service supply chain and it can be used by a large number of companies. For the successful implementation of the system, the conceptual design presented in this paper should be followed.

The expected results from the successful implementation of the system can be summarized as follows:

- Achieving significant cost savings. Maintaining various machines is challenging since it necessitates the installation and acquisition of several items. Organizing the data with the aid of a robust system integration solution can lead to significant cost savings. The expense of establishing many machines and monitoring and resolving the numerous problems that frequently emerge might be enormous. An integrated system for predictive maintenance that works effectively reduces the need for expensive preventive maintenance and upgrades.

- Enhanced support of the business processes of the service supply chain through new technology. The processes of the service supply chain, such as scheduling the supply of materials and the visits of repair workshops, will become automated, and the equipment maintenance and repair services will be vastly improved. The system will allow companies that operate and maintain assets at their customer premises to strengthen their customer base as they have at their disposal a tool for higher efficiency and effectiveness of the provided services. The companies that decide to use the system can, therefore, achieve a solid competitive advantage. The use of the system will therefore lead to an increase in the efficiency and effectiveness of the service supply chain, making it more competitive as a branch of activity for existing or even attracting new companies.

- Enabling the system's users to operate from an environment that provides a 360-degree perspective of data. Changes may be performed from a single location rather than needing the use of numerous systems, perspectives, and procedures using an integrated solution. This significantly reduces the system's complexity, which simplifies training. When staff is not required to learn various tools and systems, the onboarding process is shortened, and initiatives may be launched more quickly. Additionally, the system's user-friendly interface will simplify the interactions with it reducing the likelihood of a human mistake. Due to the data being more dependable and accurate, teams are less required to spend as much time evaluating and fixing mistakes.

- Decision-making based on factual information about all the equipment maintenance needs. When using traditional preventive maintenance techniques, decision-making is based on estimations and not on factual data about the condition of the equipment. The use of the predictive maintenance system reduces latency and simplifies the decision-making process, allowing for quicker data updates and real-time analytics. Access to near-real-time data and rapid data extraction enables the users to make better informed and timely decisions. Stakeholders are constantly informed of the equipment conditions, allowing them to flex and pivot based on factual information.

- Effective data analytics through the system's integration into the company's operations. The majority of legacy systems demand from users to interpret data from many sources. 
On contrary, the predictive maintenance system, combines data into a consolidated ecosystem, providing users with a single view of the big picture. Without a data integration solution, the company needs to compare data manually by collecting info from every single piece of equipment and then try to manage and analyze all this heterogeneous data. The predictive maintenance system solves this burden by consolidating all data into a single location, a dashboard, making monitoring and accessing information easier and faster. The system will equip companies with the necessary tools for obtaining a holistic picture of all their statistics, insights, and data in a single location. By taking a panoramic view of the data, they will be able to discover trends that were previously impossible to discover in their old environment. The effective data analytics provided by the system will facilitate performing comparisons and identifying patterns and will lead to significant time savings.

In addition to the above important expected results from the successful implementation of the system, the cooperation of the involved partners for system development has strengthened the connection and interaction of theory and practice. The participants (researcher, software developers, and industrial users) have combined their skills, knowledge, and experiences, to acquire new knowledge and an advanced system. They are set to be actively involved in the research and development of innovative activities revolving around the service supply chain and reverse supply chain operations.

The integrated implementation of the predictive maintenance of the assets, the optimal management and scheduling of inventories and purchase orders of materials and spare parts, the creation of the visit schedule for the maintenance workshops, and the organization of the whole research through standard collaborative business processes within the logistics, has not been, to the best of our knowledge, effectively addressed up to date by any other research attempt. For this reason, the research extends beyond the current technological level but at the same time is well designed and feasible as it has clear and unambiguous objectives, as presented extensively in this paper, and is based on technical approaches that integrate new technology and data analytics for predictive maintenance with methods for inventory management, purchasing management and scheduling of maintenance teams collaboratively. The adoption and integration of modern technologies of the Fourth Industrial Revolution (Industry 4.0), such as the Internet of things (IoT), machine learning and artificial intelligence algorithms, as well as cloud computing technologies and collaborative business process models, leads to an innovative and functional predictive maintenance system supporting reverse supply chain operations.

\section{Conclusions}

As it becomes clear, the contributions of this research, i.e., the methodological approach, the operational framework, and the system's architectural design, can be used as a guide to significantly enhance the maintenance of equipment supporting reverse supply chain operations. Therefore, through this research, the research question, set in the research methodology section, is answered and the problem is effectively managed.

The result of the presented research is the conceptual design of a predictive maintenance information system, supporting the reverse supply chain operations and the related maintenance and repair services. The system combines modern technologies such as IoT and cloud computing, with innovative approaches such as machine learning and artificial intelligence algorithms for the prediction of maintenance needs. Additionally, the collaborative business processes of the reverse supply chain operations, are analyzed and optimized before being interconnected with the system's functionality. The system's architectural design is also presented in this paper. Such integrated systems do not have penetration in many European companies and are therefore a pioneering approach that strengthens the successful course of the prototype system that has the potential to be implemented in real-life companies as an effective predictive maintenance tool.

The innovative implementation of data analytics methods and techniques and reverse supply chain planning methods in an integrated system, in combination with the included 
technological innovations, result in a system that successfully covers the service supply chain needs. The developed software has the ability to integrate and connect with existing information systems of a company such as the ERP system (enterprise resource planning) or the WMS (warehouse management system) that make use of data necessary for the operation of the system, such as components and spare parts that are available from each supplier, offering additional benefits to companies that decide to implement it.

The system can be used by companies that provide, monitor, and maintain equipment to third parties. This is a common situation when assets are belonging to a company but are installed on the premises of their customers. In the European market, although many companies operate in such a manner, they have mostly adopted simple maintenance management solutions without having a connection with the service supply chain and the related reverse supply chain operations. These simple solutions make no use of today's advanced technologies and cannot offer effective predictive equipment maintenance. Therefore, it becomes clear that the system can meet practical needs in maintaining equipment effectively and efficiently while introducing many innovative characteristics that make it competitive compared to other software solutions in the market and attractive to interested companies.

The advanced system is being tested on actual equipment maintenance and operation problems, aiming to overcome them and become a fully functional software tool. Further research for advanced system development is its integration with vendors' information systems in order to achieve the designed collaborative processes for materials and spare parts replenishment, just in time they are required, as well as the delivery of the required maintenance services by the mobile workshops.

To conclude, it should be noted that, today more than ever, equipment maintenance and repairs have gained a critical position in industrial companies and the impact of the service supply chain in the economic activity is significant. Therefore, the implementation of the system is expected to greatly affect the performance of companies that decide to use it, leading them to increased profits and substantial competitive advantage. These benefits, arising from the use of the system, are expected to attract more companies, thus leading to a significant potential customer base.

\begin{abstract}
Author Contributions: Conceptualization, E.P.K. and S.P.G.; methodology, E.P.K. and S.P.G.; software, S.P.G.; validation, G.D.K.; formal analysis, E.P.K. and S.P.G.; investigation, G.A.P. and G.D.K.; resources, S.P.G. and G.A.P.; data curation, E.P.K.; writing-original draft preparation, E.P.K. and S.P.G.; writing-review and editing, E.P.K. and S.P.G.; visualization, E.P.K.; supervision, S.P.G.; project administration, S.P.G.; funding acquisition, G.A.P. All authors have read and agreed to the published version of the manuscript.
\end{abstract}

Funding: This research received no external funding.

Institutional Review Board Statement: Not applicable.

Informed Consent Statement: Not applicable.

Data Availability Statement: Not applicable.

Conflicts of Interest: The authors declare no conflict of interest.

\title{
References
}

1. Rahman, S.; Subramanian, N. Factors for implementing end-of-life computer recycling operations in reverse supply chains. Int. J. Prod. Econ. 2012, 140, 239-248. [CrossRef]

2. Driessen, M.; Arts, J.; van Houtum, G.-J.; Rustenburg, J.W.; Huisman, B. Maintenance spare parts planning and control: A framework for control and agenda for future research. Prod. Plan. Control 2014, 26, 1-20. [CrossRef]

3. Zhang, R.; Chen, H. A Review of Service Supply Chain and Future Prospects. J. Serv. Sci. Manag. 2015, 8, 485-495. [CrossRef]

4. Schutz, J.; Rezg, N. Maintenance strategy for leased equipment. Comput. Ind. Eng. 2013, 66, 593-600. [CrossRef]

5. Phogat, S.; Gupta, A.K. Expected maintenance waste reduction benefits after implementation of Just in Time (JIT) philosophy in maintenance (a statistical analysis). J. Qual. Maint. Eng. 2019, 25, 25-40. [CrossRef]

6. Selcuk, S. Predictive maintenance, its implementation and latest trends. Proc. Inst. Mech. Eng. Part B J. Eng. Manuf. 2017, 231, 1670-1679. [CrossRef] 
7. Cachada, A.; Moreira, P.M.; Romero, L.; Barbosa, J.; Leitno, P.; Gcraldcs, C.A.S.; Deusdado, L.; Costa, J.; Teixeira, C.; Teixeira, J.; et al. Maintenance 4.0: Intelligent and Predictive Maintenance System Architecture. In Proceedings of the 2018 IEEE 23 rd International Conference on Emerging Technologies and Factory Automation (ETFA), Torino, Italy, 4-7 September 2018; IEEE: Piscataway, NJ, USA, 2018; pp. 139-146.

8. Hachicha, M.; Fahad, M.; Moalla, N.; Ouzrout, Y. Performance assessment architecture for collaborative business processes in BPM-SOA-based environment. Data Knowl. Eng. 2016, 105, 73-89. [CrossRef]

9. Pongpech, J.; Murthy, D.N.P.; Boondiskulchock, R. Maintenance strategies for used equipment under lease. J. Qual. Maint. Eng. 2006, 12, 52-67. [CrossRef]

10. Mehmeti, X.; Mehmeti, B.; Sejdiu, R. The equipment maintenance management in manufacturing enterprises. IFAC-PapersOnLine 2018, 51, 800-802. [CrossRef]

11. Mwanza, B.G.; Mbohwa, C. Design of a Total Productive Maintenance Model for Effective Implementation: Case Study of a Chemical Manufacturing Company. Procedia Manuf. 2015, 4, 461-470. [CrossRef]

12. Kumar, V. Customer Relationship Management. In Wiley International Encyclopedia of Marketing; John Wiley \& Sons, Ltd.: Chichester, UK, 2010.

13. Sakib, N.; Wuest, T. Challenges and Opportunities of Condition-based Predictive Maintenance: A Review. Procedia CIRP 2018, 78 , 267-272. [CrossRef]

14. Parida, A.; Kumar, U. Maintenance performance measurement (MPM): Issues and challenges. J. Qual. Maint. Eng. 2006, 12, 239-251. [CrossRef]

15. Nyemba, W.R.; Mashamba, A.; Mbohwa, C. Equipment Maintenance Challenges and Solutions for Capacity Building and Sustainability in the Training of Engineers: The Case for the University of Zimbabwe. Procedia Manuf. 2017, 7, 303-308. [CrossRef]

16. Serradilla, O.; Zugasti, E.; Zurutuza, U. Deep learning models for predictive maintenance: A survey, comparison, challenges and prospect. arXiv 2020, arXiv:2010.03207.

17. Kumar, U.; Galar, D. Maintenance in the Era of Industry 4. 0: Issues and Challenges. IT Bus. Oper. 2018, 1, $231-250$.

18. Hashemian, H.M. State-of-the-Art Predictive Maintenance Techniques. IEEE Trans. Instrum. Meas. 2011, 60, 226-236. [CrossRef]

19. $\mathrm{Hu}, \mathrm{J} . ;$ Chen, P. Predictive maintenance of systems subject to hard failure based on proportional hazards model. Reliab. Eng. Syst. Saf. 2020, 196, 106707. [CrossRef]

20. Korvesis, P.; Besseau, S.; Vazirgiannis, M. Predictive Maintenance in Aviation: Failure Prediction from Post-Flight Reports. In Proceedings of the 2018 IEEE 34th International Conference on Data Engineering (ICDE), Paris, France, 16-19 April 2018; IEEE: Piscataway, NJ, USA, 2018; pp. 1414-1422.

21. Cline, B.; Niculescu, R.S.; Huffman, D.; Deckel, B. Predictive maintenance applications for machine learning. In Proceedings of the 2017 Annual Reliability and Maintainability Symposium (RAMS), Orlando, FL, USA, 23-26 January 2017; IEEE: Piscataway, NJ, USA, 2017; pp. 1-7.

22. Dalzochio, J.; Kunst, R.; Pignaton, E.; Binotto, A.; Sanyal, S.; Favilla, J.; Barbosa, J. Machine learning and reasoning for predictive maintenance in Industry 4.0: Current status and challenges. Comput. Ind. 2020, 123, 103298. [CrossRef]

23. Guo, S.; Shen, B.; Choi, T.-M.; Jung, S. A review on supply chain contracts in reverse logistics: Supply chain structures and channel leaderships. J. Clean. Prod. 2017, 144, 387-402. [CrossRef]

24. Govindan, K.; Bouzon, M. From a literature review to a multi-perspective framework for reverse logistics barriers and drivers. J. Clean. Prod. 2018, 187, 318-337. [CrossRef]

25. Julianelli, V.; Caiado, R.G.G.; Scavarda, L.F.; Cruz, S.P.d.M.F. Interplay between reverse logistics and circular economy: Critical success factors-based taxonomy and framework. Resour. Conserv. Recycl. 2020, 158, 104784. [CrossRef]

26. Dong, L.; Mingyue, R.; Guoying, M. Application of Internet of Things Technology on Predictive Maintenance System of Coal Equipment. Procedia Eng. 2017, 174, 885-889. [CrossRef]

27. Pech, M.; Vrchota, J.; Bednář, J. Predictive Maintenance and Intelligent Sensors in Smart Factory: Review. Sensors 2021, 21, 1470. [CrossRef]

28. Li, Z.; Wang, Y.; Wang, K.-S. Intelligent predictive maintenance for fault diagnosis and prognosis in machine centers: Industry 4.0 scenario. Adv. Manuf. 2017, 5, 377-387. [CrossRef]

29. Civerchia, F.; Bocchino, S.; Salvadori, C.; Rossi, E.; Maggiani, L.; Petracca, M. Industrial Internet of Things monitoring solution for advanced predictive maintenance applications. J. Ind. Inf. Integr. 2017, 7, 4-12. [CrossRef]

30. Dossou, P.-E. Impact of Sustainability on the supply chain 4.0 performance. Procedia Manuf. 2018, 17, 452-459. [CrossRef]

31. Makris, D.; Hansen, Z.N.L.; Khan, O. Adapting to supply chain 4.0: An explorative study of multinational companies. Supply Chain Forum An Int. J. 2019, 20, 116-131. [CrossRef]

32. Lee, J.; Ardakani, H.D.; Yang, S.; Bagheri, B. Industrial Big Data Analytics and Cyber-physical Systems for Future Maintenance \& Service Innovation. Procedia CIRP 2015, 38, 3-7. [CrossRef]

33. Kan, C.; Yang, H.; Kumara, S. Parallel computing and network analytics for fast Industrial Internet-of-Things (IIoT) machine information processing and condition monitoring. J. Manuf. Syst. 2018, 46, 282-293. [CrossRef]

34. Osborne, J. Internet of Things and Cloud Computing. In Internet of Things and Data Analytics Handbook; John Wiley \& Sons, Inc.: Hoboken, NJ, USA, 2016; pp. 683-698.

35. Cañas, H.; Mula, J.; Campuzano-Bolarín, F. A General Outline of a Sustainable Supply Chain 4.0. Sustainability 2020, 12, 7978. [CrossRef] 
36. Tjahjono, B.; Esplugues, C.; Ares, E.; Pelaez, G. What does Industry 4.0 mean to Supply Chain? Procedia Manuf. 2017, 13, 1175-1182. [CrossRef]

37. Ayvaz, S.; Alpay, K. Predictive maintenance system for production lines in manufacturing: A machine learning approach using IoT data in real-time. Expert Syst. Appl. 2021, 173, 114598. [CrossRef]

38. Lo, C.-C.; Yu, S.-W. A two-phased evolutionary approach for intelligent task assignment \& scheduling. In Proceedings of the 11th International Conference on Natural Computation (ICNC), Zhangjiajie, China, 15-17 August 2015; IEEE: Piscataway, NJ, USA, 2015; pp. 1092-1097.

39. Chiu, Y.-C.; Cheng, F.-T.; Huang, H.-C. Developing a factory-wide intelligent predictive maintenance system based on Industry 4.0. J. Chinese Inst. Eng. 2017, 40, 562-571. [CrossRef]

40. Schmidt, B.; Wang, L.; Galar, D. Semantic Framework for Predictive Maintenance in a Cloud Environment. Procedia CIRP 2017, 62, 583-588. [CrossRef]

41. Zonta, T.; da Costa, C.A.; da Rosa Righi, R.; de Lima, M.J.; da Trindade, E.S.; Li, G.P. Predictive maintenance in the Industry 4.0: A systematic literature review. Comput. Ind. Eng. 2020, 150, 106889. [CrossRef]

42. Lu, Y. Industry 4.0: A survey on technologies, applications and open research issues. J. Ind. Inf. Integr. 2017, 6, 1-10. [CrossRef]

43. Ding, S.-H.; Kamaruddin, S. Maintenance policy optimization-literature review and directions. Int. J. Adv. Manuf. Technol. 2015, 76, 1263-1283. [CrossRef]

44. Purohit, B.S.; Kumar Lad, B. Production and maintenance planning: An integrated approach under uncertainties. Int. J. Adv. Manuf. Technol. 2016, 86, 3179-3191. [CrossRef]

45. Zhang, W.; Yang, D.; Wang, H. Data-Driven Methods for Predictive Maintenance of Industrial Equipment: A Survey. IEEE Syst. J. 2019, 13, 2213-2227. [CrossRef]

46. Wang, J.; Liang, Y.; Zheng, Y.; Gao, R.X.; Zhang, F. An integrated fault diagnosis and prognosis approach for predictive maintenance of wind turbine bearing with limited samples. Renew. Energy 2020, 145, 642-650. [CrossRef]

47. Ramuhalli, P.; Walker, C.; Agarwal, V.; Lybeck, N. Development of Prognostic Models Using Plant Asset Data; Oak Ridge National Lab: Oak Ridge, TN, USA, 2020.

48. Ruschel, E.; Santos, E.A.P.; Loures, E.d.F.R. Industrial maintenance decision-making: A systematic literature review. J. Manuf. Syst. 2017, 45, 180-194. [CrossRef]

49. Bumblauskas, D.; Gemmill, D.; Igou, A.; Anzengruber, J. Smart Maintenance Decision Support Systems (SMDSS) based on corporate big data analytics. Expert Syst. Appl. 2017, 90, 303-317. [CrossRef]

50. Liu, X.; He, D.; Lodewijks, G.; Pang, Y.; Mei, J. Integrated decision making for predictive maintenance of belt conveyor systems. Reliab. Eng. Syst. Saf. 2019, 188, 347-351. [CrossRef]

51. Ravitch, S.M.; Carl, N.M. Qualitative Research: Bridging the Conceptual, Theoretical, and Methodological, 2nd ed.; SAGE Publications: Thousand Oaks, CA, USA, 2019; pp. 1-624.

52. Mora, M.; Ovsei, G.; Paradice, D.; Cervantes, F. The Case for Conceptual Research in Information Systems. In Proceedings of the CONF-IRM 2008, Niagara Falls, ON, Canada, 18-20 May 2008; pp. 1-11.

53. Bousdekis, A.; Lepenioti, K.; Apostolou, D.; Mentzas, G. Decision Making in Predictive Maintenance: Literature Review and Research Agenda for Industry 4.0. IFAC-PapersOnLine 2019, 52, 607-612. [CrossRef]

54. Compare, M.; Baraldi, P.; Zio, E. Challenges to IoT-Enabled Predictive Maintenance for Industry 4.0. IEEE Internet Things J. 2020, 7, 4585-4597. [CrossRef] 